\title{
The Communicative Effects of a Cup of Coffee on Dyadic Conversation
}

\author{
K. Yokomitsu' ${ }^{1}$, K. Fujiwara ${ }^{2}$ \\ ${ }^{1}$ College of Comprehensive Psychology, Ritsumeikan University, Ibaraki, Japan \\ ${ }^{2}$ Faculty of Human Sciences, Osaka University of Economics, Osaka, Japan \\ Email: ken.fuji@osaka-ue.ac.jp
}

How to cite this paper: Yokomitsu, K., \& Fujiwara, K. (2019). The Communicative Effects of a Cup of Coffee on Dyadic Conversation. Psychology, 10, 1361-1370. https://doi.org/10.4236/psych.2019.1010087

Received: February 21, 2019

Accepted: July 23, 2019

Published: July 26, 2019

Copyright (c) 2019 by author(s) and Scientific Research Publishing Inc. This work is licensed under the Creative Commons Attribution International License (CC BY 4.0).

http://creativecommons.org/licenses/by/4.0/ (c) () Open Access

\begin{abstract}
Findings from previous studies have suggested that environmental factors affect the quality of communication. Although the impact of several environmental factors such as fixed- and semifixed-feature elements has been investigated, the present pre-registered study focuses on a more casual environmental factor: the presence of a cup of coffee. In the present study, 118 non-student participants engaged in a dyadic, face-to-face, unstructured conversation with a stranger of the same gender. Participants with a cup of coffee reported an identical level of rapport (a type of close and positive communication), friendliness, vigor-activity, and tension-anxiety as participants with a cup of water (control group 1). They also reported higher rapport friendliness and vigor-activity than participants in the no drink condition (control group 2), though the difference in rapport did not reach the level of significance. However, for rapport, the positive impact of coffee was salient in individuals who held a strong belief in the communicative effect of coffee. The findings indicate that a cup of coffee can be an environmental factor that potentially enhances the quality of communication.
\end{abstract}

\section{Keywords}

Coffee, Water, Rapport, POMS 2, Face-to-Face, Dyadic Conversation

\section{Introduction}

The findings from numerous studies have demonstrated that environmental factors affect communication. Environmental and artifactual features can be categorized as fixed- and semifixed-feature elements (Hall, 1966). Whereas fixed-feature elements are relatively permanent or slow to change such as floors, ceilings, and walls (Rapoport, 1990), semifixed-feature elements include the ar- 
rangement of movable objects such as tables and chairs (White, 1953; see also Burgoon, Guerrero, \& Floyd, 2010; Knapp, Hall, \& Horgan, 2013).

However, it has not yet been investigated whether a common staple of daily life like a cup of coffee (which also happens to be a movable object) can affect communication. In the present study, the impact of a cup of coffee on communication is examined from a psychological perspective, with a focus on rapport.

Recent literature has illustrated that the presence of personal belongings influences the quality of communication. For instance, a smartphone on the table can be a distraction in face-to-face communication (Misra, Cheng, Genevie, \& Yuan, 2014) since the smartphone attracts the owner's attention from the communication partner and impacts their interaction (Dwyer, Kushlev, \& Dunn, 2018).

The present study seeks to investigate how coffee, one of the largest consumables all over the world, affects the perception of rapport in a conversation. In 2017, coffee consumption reached 1.5 million kilograms in the U.S. and 0.4 million kilograms in Japan (International Coffee Organization, 2018). It would not be an exaggeration to say that coffee is a part of everyday life for many people and could thus be an environmental factor in communication.

This assumption is indirectly supported by research findings using questionnaires. Coffee contains caffeine, which is the most widely consumed psychoactive drug in the world (Bastia \& Schwarzschild, 2003; James, 1997). Huntley and Juliano (2012) confirmed that people believe caffeine has a social/mood enhancement effect, which implies that a cup of coffee can facilitate smooth and/or affiliative communication. Japanese research has shown that coffee can increase one's positive mood and promote social relationships (Yokomitsu et al., 2015). However, the positive impact of coffee on social interaction has not been examined experimentally. In addition, it remains unclear to what extent an expectation or belief in the socially enhancing effect of coffee strengthens the actual effect. Therefore, the present study investigates the social enhancement effect of coffee by focusing on the effect of coffee, not caffeine. The participants in the study engaged in a face-to-face conversation immediately after consuming coffee (i.e., before the onset of the effect of caffeine).

Rapport refers to a type of close, positive communication in which individuals experience a harmonious connection and a common understanding (Tickle-Degnen \& Rosenthal, 1990; Tickle-Degnen, 2006) consisting of three elements: mutual attentiveness, positivity, and interpersonal coordination (Tickle-Degnen, 2006). Given the possible social enhancement effect of coffee, the following hypotheses were tested:

H1a: Interactants with a cup of coffee will report higher rapport compared with interactants with a cup of water or without drinks.

H2a: Interactants with a strong belief in the communicative effect of coffee will report higher rapport with a cup of coffee.

In addition, the second edition of the Profile of Mood States (POMS 2) (Lin, Hsiao, \& Wang, 2014) subscale was also used to evaluate mood before and after 
the conversation. Thus, the additional hypotheses were made:

Interactants with a cup of coffee will report higher friendliness (H1b) and vigor-activity (H1c) compared with interactants with a cup of water or without drinks, whereas they will report lower tension-anxiety compared with those in the water and no drink condition (H1d).

Also, interactants with a strong belief in the communicative effect of coffee in the coffee condition will report higher friendliness $(\mathrm{H} 2 \mathrm{~b})$, vigor-activity $(\mathrm{H} 2 \mathrm{c})$, and lower tension-anxiety (H2d).

\section{Material and Methods}

\subsection{Ethical Statement}

The present study was approved by the ethical committee of the Faculty of $\mathrm{Hu}$ man Sciences in the Osaka University of Economics and was pre-registered (ref. UMIN000031212;

https://upload.umin.ac.jp/cgi-open-bin/ctr e/ctr view.cgi?recptno=R000035641).

\subsection{Participants}

Participants in the study included 118 Japanese adults (58 females and 60 males; $M_{\text {age }}=44.96$ years, $\left.S D_{\text {age }}=13.78\right)$. Recruitment was conducted in cooperation with a Japanese research company (Marketing Service, co. Ltd.). The participants were recruited using an online advertisement named "Research on consumption of coffee." The inclusion criteria were that participants were a) aged 20 - 69 years and b) individuals who usually consume coffee. The participants were asked not to consume any food, drink, alcohol, or tobacco within one hour of the start of the experiment.

\subsection{Procedures}

First, participants who met the eligibility criteria were divided into pairs, and each pair was composed of individuals who did not know each other and were of the same sex and generation. Through a stratified randomized design, the pairs were then allocated to either the experimental group (consume a cup of coffee), control group 1 (consume a cup of water), or control group 2 (consume nothing). The stratification was conducted in accordance with participants' age and gender. A random number table was used for the allocation. The study took place in two rooms at the second author's institution.

The participants entered the waiting room an hour before the experiment started. Prior to giving their informed consent, the participants were not told that their rapport would be measured in order to reduce the risk of response bias. For this reason, the participants were told that the research consisted of a conversation experiment, but the word "rapport" was not mentioned. Then, participants were informed of the duration of the experiment and were informed that they could quit whenever they wanted. The protection of personal information was also explained orally and in writing. Thereafter, the participants' writ- 
ten consent to participate was obtained.

Next, the participants were asked to engage in a 15 minute conversation experiment. The experimental group had a conversation while consuming coffee. The control groups consumed either water or nothing, respectively. In the coffee/water condition, both conversation partners could drink coffee/water. Commercial-release drip coffee and water were used. The participants sat approximately 80 centimeters apart from each other. Between the participants, there was a square table, and either two cups of coffee or water set on the table. Before the conversation, the participants in the coffee/water condition were asked to have a sip of their own coffee/water. Then, they were allowed to drink their coffee/water during the conversation. After the conversation, the participants' perception of their rapport during the conversation was measured. The experiment concluded with a debriefing in which the participants were informed that their rapport was measured.

\subsection{Questionnaire}

Bernieri et al.'s (1996) scale was employed to measure participants' rapport. This 18-item measure (ranging from 0 "not at all," to 8 "extremely") asked participants to "rate the interaction you just experienced between you and your partner on each of the characteristics listed" and included items such as "well-coordinated," "boring," and "cooperative." The reliability of this scale was high $(\alpha=0.93)$.

Mood states before and after the conversation were measured by POMS 2 (Lin et al., 2014; for the Japanese translation see Yokoyama, 2015). In the present study, the subscales of friendliness, vigor-activeness, and tension-anxiety were used (before the conversation: $\alpha=0.87,0.95,0.89$, respectively; after the conversation: $\alpha=0.89,0.92,0.81$, respectively).

To measure the participants' belief in the communicative effect of coffee, the Shikohin's Psychological Effects Questionnaire (SPEQ) (Yokomitsu et al., 2017) was employed. This scale consists of four factors: self-empowerment, acquisition of positive mood, improving concentration, and facilitating communication. Belief in a communicative effect has six items (ranging from 1 "not at all," to 7 "extremely"). The reliability of this scale was also high $(\alpha=0.89)$.

\section{Results}

An intraclass correlation (ICC) was confirmed because participants' feelings of rapport, friendliness, vigor-activeness, and tension-anxiety might be correlated with each other in a dyad; the ICC coefficient was $0.216,0.105,0.102,-0.104$, respectively. Furthermore, multilevel modeling was employed to estimate the impact of coffee on rapport. Similarly, the subscale of POMS 2 was analyzed using multilevel modeling to keep the analysis consistent. The descriptive statistics in this study are shown in Table 1.

In the multilevel linear model, the main effect of belief in the communicative effect of coffee, gender, and condition were included, as well as the interaction 
Table 1. Descriptive statistics of rapport and POMS 2 scale.

\begin{tabular}{|c|c|c|c|c|c|c|c|}
\hline & & \multicolumn{3}{|c|}{ Female } & \multicolumn{3}{|c|}{ Male } \\
\hline & & Coffee & Water & No drink & Coffee & Water & No drink \\
\hline \multirow[t]{2}{*}{ Rapport } & $M$ & 7.07 & 6.98 & 6.94 & 6.64 & 6.75 & 6.08 \\
\hline & $S D$ & 0.75 & 0.88 & 0.95 & 0.93 & 0.86 & 0.84 \\
\hline \multirow[t]{2}{*}{ Belief } & $M$ & 5.81 & 5.57 & 5.54 & 5.09 & 5.57 & 5.14 \\
\hline & $S D$ & 0.60 & 0.77 & 0.98 & 1.26 & 0.58 & 0.71 \\
\hline \multicolumn{8}{|l|}{ POMS 2} \\
\hline \multirow{3}{*}{$\begin{array}{c}\text { Pre } \\
\text { Friendliness }\end{array}$} & $M$ & 1.93 & 1.83 & 1.73 & 1.49 & 1.94 & 1.63 \\
\hline & $S D$ & 0.80 & 0.94 & 0.81 & 1.13 & 0.54 & 0.68 \\
\hline & $S D$ & 0.62 & 1.12 & 0.86 & 0.89 & 0.71 & 0.70 \\
\hline Pre & $M$ & 1.25 & 1.41 & 1.63 & 1.23 & 1.41 & 1.21 \\
\hline Vigor-Activity & $S D$ & 0.81 & 1.24 & 0.79 & 1.35 & 0.86 & 0.76 \\
\hline Pre & $M$ & 0.83 & 1.16 & 0.80 & 0.88 & 0.90 & 1.07 \\
\hline Tension-Anxiety & $S D$ & 0.62 & 1.12 & 0.86 & 0.89 & 0.71 & 0.70 \\
\hline Post & $M$ & 2.51 & 2.27 & 2.08 & 2.08 & 2.39 & 1.77 \\
\hline Friendliness & $S D$ & 0.84 & 0.84 & 1.00 & 1.13 & 0.69 & 0.91 \\
\hline Post & $M$ & 2.13 & 2.09 & 1.96 & 2.06 & 2.05 & 1.56 \\
\hline Vigor-Activity & $S D$ & 1.04 & 0.97 & 0.98 & 1.33 & 0.93 & 0.91 \\
\hline Post & $M$ & 0.41 & 0.57 & 0.48 & 0.33 & 0.45 & 0.65 \\
\hline Tension-Anxiety & $S D$ & 0.40 & 0.81 & 0.54 & 0.40 & 0.45 & 0.69 \\
\hline
\end{tabular}

effect of belief and condition. For the subscale of POMS 2, the same subscale measured before the conversation was also included as a control variable (Table 2).

For rapport, the main effect of gender revealed that female participants reported higher rapport $(M=6.98, S D=0.86)$ compared with male participants $(M=6.49, S D=0.91)$, a finding which was approaching but not reaching significance $(p=0.053)$. Furthermore, participants in the coffee condition reported higher rapport $(M=6.86, S D=0.86)$ compared with participants in the no drink condition $(M=6.46, S D=0.98)$, which was not found to be significant either. The differences in the level of perceived rapport between the coffee and water conditions $(M=6.86, S D=0.87)$ were not found to be significant either. Belief in the communicative effect of coffee $(M=5.45, S D=0.87)$ was found to have a significant positive impact on rapport. A simple slope analysis revealed that belief had a significant impact in the coffee and no drink conditions, but not in the water condition (Figure 1).

For friendliness mood, a significant difference was found between the participants in the coffee condition $(M=2.30, S D=1.00)$ and the no drink condition $(M=1.94, S D=0.97)(p=0.044)$, whereas the difference between the coffee and water condition $(M=2.33, S D=0.76)$ and the no drink and water condition was 
Table 2. The impact of coffee and belief in the coffee's communicative effect on rapport and mood.

\begin{tabular}{|c|c|c|c|c|c|c|c|c|}
\hline & \multicolumn{2}{|c|}{ Rapport } & \multicolumn{2}{|c|}{$\begin{array}{c}\text { Post } \\
\text { Friendliness }\end{array}$} & \multicolumn{2}{|c|}{$\begin{array}{c}\text { Post } \\
\text { Vigor-Activity }\end{array}$} & \multicolumn{2}{|c|}{$\begin{array}{c}\text { Post } \\
\text { Tension-Anxiety }\end{array}$} \\
\hline & $\mathrm{b}$ & $S E$ & b & $S E$ & $\mathrm{~b}$ & $S E$ & $\mathrm{~b}$ & $S E$ \\
\hline \multicolumn{9}{|l|}{ Fixed effect } \\
\hline Intercept & $7.02^{\star *}$ & 0.16 & $1.14^{* *}$ & 0.16 & $1.25^{\star \star}$ & 0.15 & $0.03^{* *}$ & 0.03 \\
\hline Belief (centered) & $0.27^{\star \star}$ & 0.13 & $0.30^{* *}$ & 0.10 & $-0.35^{\star *}$ & 0.11 & $-0.01^{\star *}$ & 0.07 \\
\hline $\begin{array}{c}\text { Gender } \\
(\text { female }=0, \text { male }=1)\end{array}$ & $-0.32^{\star \star}$ & 0.16 & $0.01^{* *}$ & 0.11 & $0.05^{\star *}$ & 0.13 & $-0.05^{\star \star}$ & 0.08 \\
\hline $\begin{array}{l}\text { Condition: Water } \\
(\text { no }=1, \text { yes }=1)\end{array}$ & $-0.01^{\star *}$ & 0.19 & $-0.10^{\star \star}$ & 0.13 & $-0.17^{\star *}$ & 0.16 & $0.07^{\star \star}$ & 0.10 \\
\hline $\begin{array}{l}\text { Condition: No drink } \\
(\text { no }=1, \text { yes }=1)\end{array}$ & $-0.30^{\star *}$ & 0.20 & $-0.28^{\star \star}$ & 0.14 & $-0.39^{\star *}$ & 0.16 & $0.17^{\star \star}$ & 0.10 \\
\hline $\begin{array}{c}\text { Condition: Water } \\
\times \text { Belief }\end{array}$ & $-0.14^{\star *}$ & 0.22 & $-0.18^{\star \star}$ & 0.17 & $-0.05^{\star *}$ & 0.20 & $-0.05^{\star *}$ & 0.13 \\
\hline $\begin{array}{c}\text { Condition: No drink } \\
\times \text { Belief }\end{array}$ & $0.42^{* *}$ & 0.20 & $0.16^{\star *}$ & 0.15 & $-0.03^{\star *}$ & 0.17 & $--0.13^{\star *}$ & 0.11 \\
\hline Pre Friendliness & & & $0.68^{* *}$ & 0.07 & & & & \\
\hline Pre Vigor-Activity & & & & & $-0.67^{\star *}$ & 0.07 & & \\
\hline Pre Tension-Anxiety & & & & & & & $0.43^{* *}$ & 0.05 \\
\hline \multicolumn{9}{|l|}{ Random effect } \\
\hline Dyad & \multicolumn{2}{|c|}{0.09} & \multicolumn{2}{|c|}{$<0.00$} & \multicolumn{2}{|c|}{$<0.00$} & \multicolumn{2}{|c|}{0.003} \\
\hline Residual & \multicolumn{2}{|c|}{0.55} & \multicolumn{2}{|c|}{$<0.36$} & \multicolumn{2}{|c|}{$<0.48$} & \multicolumn{2}{|c|}{0.19} \\
\hline AIC (null model) & \multicolumn{2}{|c|}{319.18} & \multicolumn{2}{|c|}{324.62} & \multicolumn{2}{|c|}{350.83} & \multicolumn{2}{|c|}{211.60} \\
\hline AIC & \multicolumn{2}{|c|}{306.38} & \multicolumn{2}{|c|}{246.89} & \multicolumn{2}{|c|}{280.63} & \multicolumn{2}{|c|}{179.14} \\
\hline
\end{tabular}

Note. ${ }^{*} p<0.05,{ }^{* *} p<0.01$. The variable "Condition: Water" and "Condition: No drink" are categorical; "Condition: Coffee" is used as an anchor in the model. Belief refers to the belief in the communicative effect of coffee, which is centered using the grand mean.

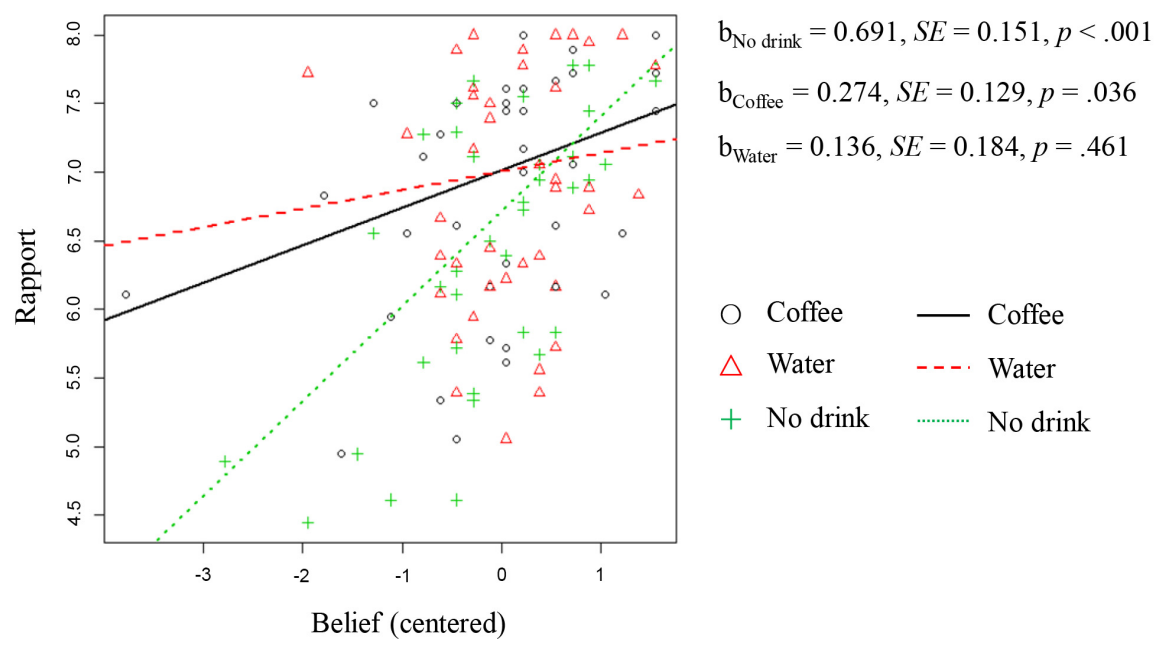

Figure 1. A simple slope analysis of the interaction effect of condition and belief in the communicative effect of coffee on rapport. The black solid line represents the simple slope of the coffee condition, the red dashed line the water condition, and the green dotted line the no drink condition. 
not found to be significant ( $p=0.467,0.197$, respectively). A simple slope analysis revealed that belief had a significant impact in the coffee and no drink conditions, but not in the water condition (Figure 2).

For vigor-activity mood, a significant difference was found between the participants in the coffee condition $(M=2.10, S D=1.18)$ and the no drink condition $(M=1.77, S D=0.98)(p=0.015)$, whereas the difference between the coffee and water condition $(M=2.07, S D=0.94)$ and the no drink and water condition were not found to be significant ( $p=0.270,0.176$, respectively). A simple slope analysis revealed that belief had a significant impact in the coffee and no drink conditions, but not in the water condition (Figure 3).

For tension-anxiety mood, no significant difference was found between the coffee $(M=0.37, S D=0.40)$ and no drink condition $(M=0.59, S D=0.62)$, the water $(M=0.51, S D=0.65)$ and no drink condition, and the water and coffee condition ( $p=0.103,0.349,0.479$, respectively). A simple slope analysis revealed that belief had no significant impact in all the conditions (Figure 4).

\section{Discussion}

The present study investigated the impact of a cup of coffee on face-to-face, unstructured, dyadic conversations. The results showed that interactants with a cup of coffee reported slightly higher rapport compared to those with no drinks. However, the level of rapport was not different from interactants with a cup of water, which did not support hypothesis H1a. Furthermore, the participants in the coffee condition showed similar levels of friendliness, vigor-activity, and tension-anxiety compared with participants in the water condition, although their friendliness and vigor-activity mood were significantly higher than that of the no drink condition, which indicated that $\mathrm{H} 1 \mathrm{~b}, \mathrm{H} 1 \mathrm{c}$, and $\mathrm{H} 1 \mathrm{~d}$ were also not supported.

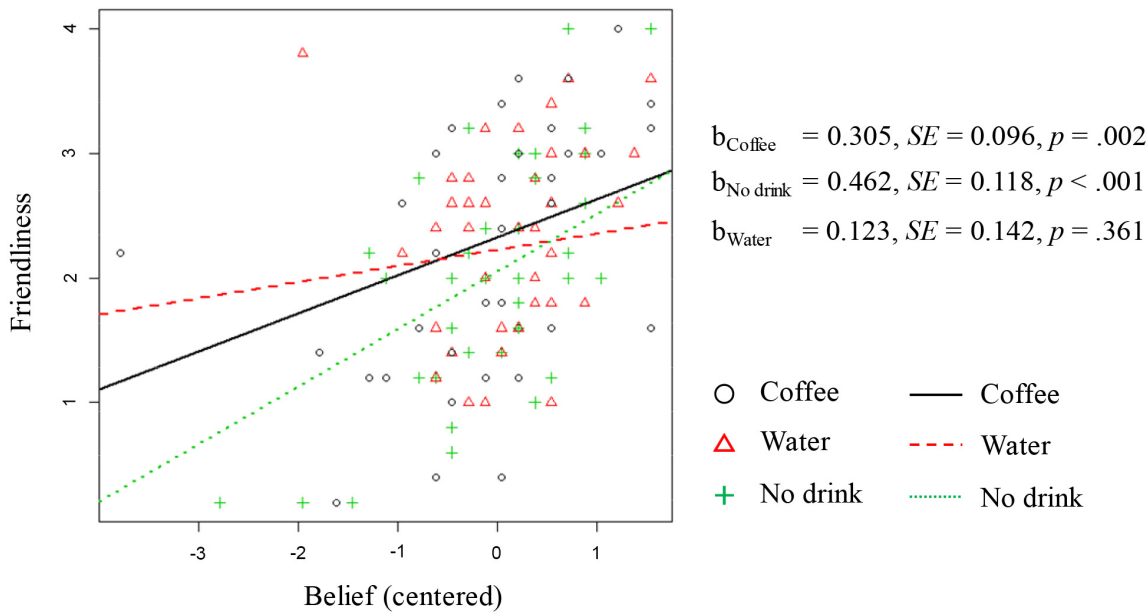

Figure 2. A simple slope analysis of the interaction effect of condition and belief in the communicative effect of coffee on friendliness mood after the conversation. The black solid line represents the simple slope of the coffee condition, the red dashed line the water condition, and the green dotted line the no drink condition. 


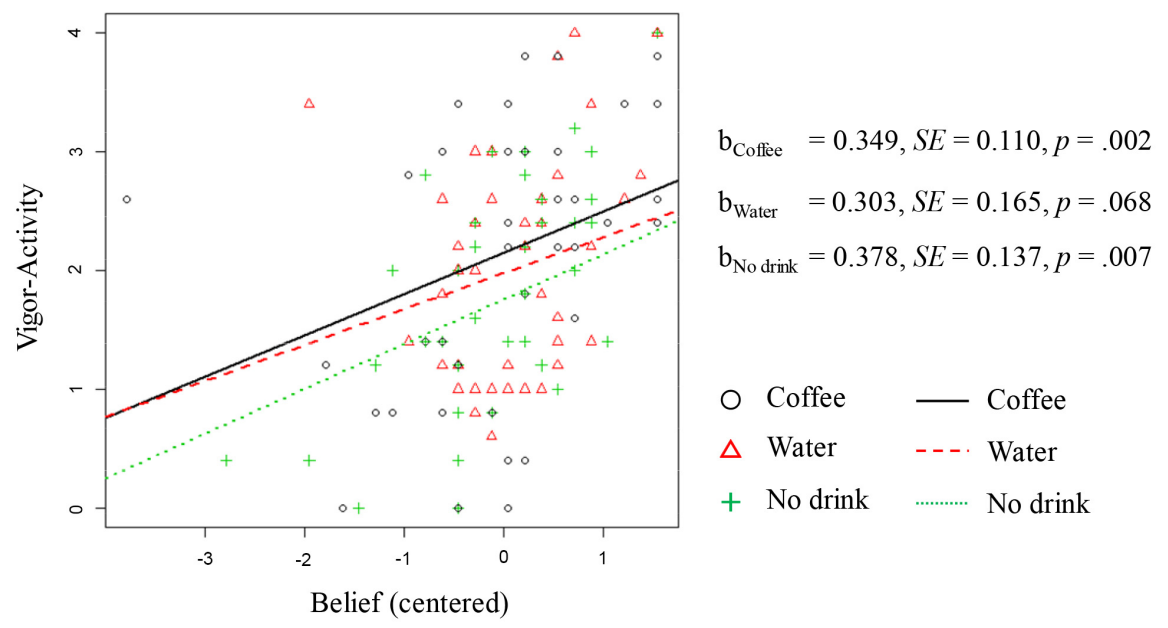

Figure 3. A simple slope analysis of the interaction effect of condition and belief in the communicative effect of coffee on vigor-activity mood after the conversation. The black solid line represents the simple slope of the coffee condition, the red dashed line the water condition, and the green dotted line the no drink condition.

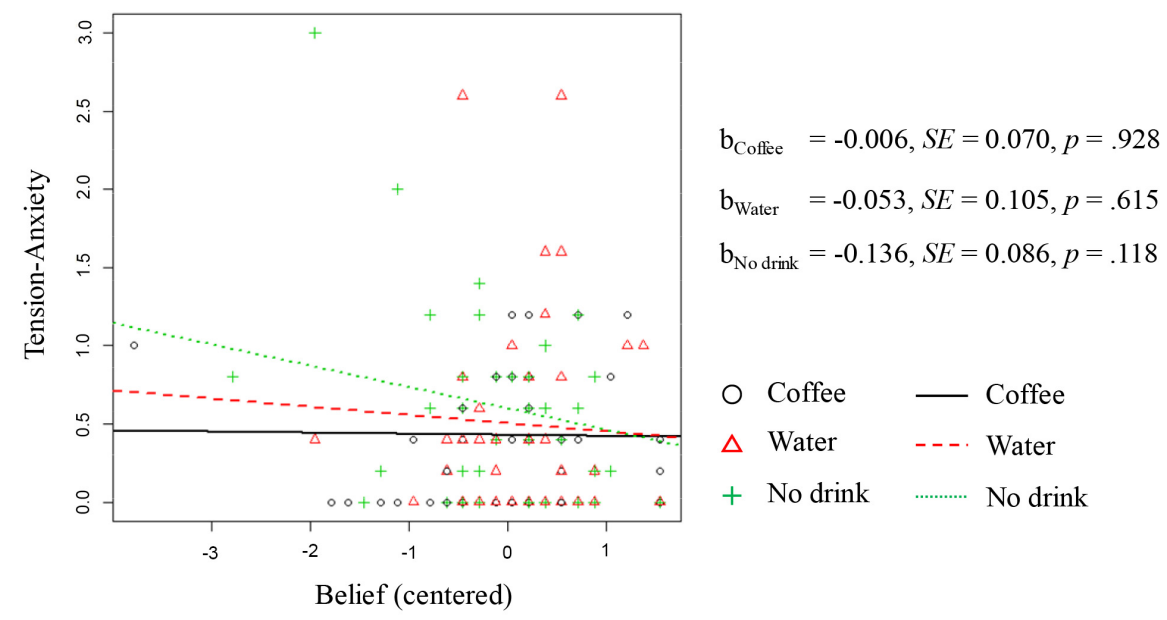

Figure 4. A simple slope analysis of the interaction effect of condition and belief in the communicative effect of coffee on tension-anxiety mood after the conversation. The black solid line represents the simple slope of the coffee condition, the red dashed line the water condition, and the green dotted line the no drink condition.

However, the positive impact of coffee on rapport, friendliness, and vigor-activity was found to be salient for participants with a strong belief in the communicative effect of coffee. This positive impact was also significant in the no drink condition, whereas it was not significant in the water condition. In other words, the positive impact of belief in the communicative effect of coffee was selectively seen in two drink conditions, which partially supported H2a, $\mathrm{H} 2 \mathrm{~b}$, and $\mathrm{H} 2 \mathrm{c}$. This study thus provides new evidence that a cup of coffee can have an impact on communication. It is noteworthy that the results of this study do not concern caffeine since the influence of caffeine appears approximately 60 - 90 minutes after coffee consumption (Ruxton, 2008), and thus caffeine could not have had any physical influence during the conversations in the present 
study.

It is important to discuss a specific limitation of the present study which was that the mediator was not clearly indicated. As mentioned above, although caffeine could not have been a mediator, one possible mediator could have been the feeling of relaxation. A previous study indicated that people expect to feel relaxed as a result of coffee consumption (Yokomitsu et al., 2015). Such a relaxing effect could have facilitated the participants enjoying their conversation.

Another possible mediator could have been consuming a similar drink together. In the present study, the participants could see what their partner had during the conversation, which allowed them to know they were consuming the same kind of drink (or no drink). Thus, the level of rapport was not significantly different between the coffee and water condition because the experience of having a drink (no matter which type of drink it was) could facilitate communication. In future research, conversations with different types of drinks (e.g., coffee for one interactant and water for the other) could be investigated.

\section{Acknowledgements}

We thank R. Hoso, H. Kikuchi, M. Maruta, A. Miyata, K. Nishino, R. Takenaka, $\mathrm{H}$. Tamamatsu, and T. Toda for their help with data collection.

\section{Funding}

This study was supported by a research funding from Tobacco Academic Studies Center (TASC).

\section{Conflicts of Interest}

The authors declare no conflicts of interest regarding the publication of this paper.

\section{References}

Bastia, E., \& Schwarzschild, M. A. (2003). DARPP Chocolate: A Caffeinated Morsel of Striatal Signaling. Science Signaling, 2003, PE2.

Bernieri, F. J., Gillis, J. S., Davis, J. M., \& Grahe, J. E. (1996). Dyad Rapport and the Accuracy of Its Judgment across Situations: A Lens Model Analysis. Journal of Personality and Social Psychology, 71, 110-129. https://doi.org/10.1037/0022-3514.71.1.110

Burgoon, J. K., Guerrero, L. K., \& Floyd, K. (2010). Nonverbal Communication. Boston, MA: Ally \& Bacon.

Dwyer, R. J., Kushlev, K., \& Dunn, E. W. (2018). Smartphone Use Undermines Enjoyment of Face-to-Face Social Interactions. Journal of Experimental Social Psychology, 78, 233-239. https://doi.org/10.1016/j.jesp.2017.10.007

Hall, E. T. (1966). The Hidden Dimension. Garden City, NY: Doubleday.

Huntley, E. D., \& Juliano, L. M. (2012). The Caffeine Expectancy Questionnaire (CaffEQ): Construction, Psychometric Properties, and Associations with Caffeine Use, Caffeine Dependence, and Other Related Variables. Psychological Assessment, 24, 592-607. https://doi.org/10.1037/a0026417 
International Coffee Organization (2018). The Current State of the Global Coffee Trade. http://www.ico.org/monthly coffee trade stats.asp

James, J. E. (1997). Understanding Caffeine: A Biobehavioral Analysis. Thousand Oaks, CA: Sage.

Knapp, M. L., Hall, J. A., \& Horgan, T. G. (2013). Nonverbal Communication in Human Interaction (8th ed.). Boston, MA: Cengage Learning.

Lin, S., Hsiao, Y.-Y., \& Wang, M. (2014). Review of the Profile of Mood States 2nd Edition (POMS 2). Journal of Psychoeducational Assessment, 32, 273-277. https://doi.org/10.1177/0734282913505995

Misra, S., Cheng, L., Genevie, J., \& Yuan, M. (2014). The iPhone Effect: The Quality of In-Person Social Interactions in the Presence of Mobile Devices. Environment and Behavior, 48, 275-298. https://doi.org/10.1177/0013916514539755

Rapoport, A. (1990). The Meaning of the Built Environment: A Nonverbal Communication Approach (2nd ed.). Tucson, AZ: University of Arizona Press.

Ruxton, S. H. C. (2008). The Impact of Caffeine on Mood, Cognitive Function, Performance and Hydration: A Review of Benefits and Risks. Nutrition Bulletin, 33, 15-25. https://doi.org/10.1111/j.1467-3010.2007.00665.x

Tickle-Degnen, L. (2006). Nonverbal Behavior and Its Functions in the Ecosystem of Rapport. In V. Manusov, \& M. Patterson (Eds.), The SAGE Handbook of Nonverbal Communication (pp. 381-399). Thousand Oaks, CA: Sage. https://doi.org/10.4135/9781412976152.n20

Tickle-Degnen, L., \& Rosenthal, R. (1990). The Nature of Rapport and Its Nonverbal Correlates. Psychological Inquiry, 1, 285-293. https://doi.org/10.1207/s15327965pli0104 1

White, A. G. (1953). The Patient Sits Down: A Clinical Note. Psychosomatic Medicine, 15, 256-257. https://doi.org/10.1097/00006842-195305000-00005

Yokomitsu, K., Kanai, Y., Hrai, H., Iizuka, T., Akatsuka, T., Sato, K. et al. (2017). Development of the Shikohin's Psychological Effects Questionnaire. Behavioral Science Research, 55, 103-115.

Yokomitsu, K., Kanai, Y., Matsuki, S., Hirai, H., Iizuka, T., Wakasa, K. et al. (2015). The Psychological Effects of Taking in "Shikohin": A Cross-Sectional Exploratory Study. Japanese Journal of Psychology, 86, 354-360. https://doi.org/10.4992/jipsy.86.14321

Yokoyama, K. (2015). Profile of Mood States (2nd ed.). Tokyo: Kanekosyobo. 